\title{
Potential environmental fate of elsinochrome $A$, a perylenequinone toxin produced in culture by bindweed biocontrol fungus Stagonospora convolvuli LA39
}

\author{
M.O. Ahonsi - D. Boss - M. Maurhofer · G. Défago
}

(C) Springer Science + Business Media, LLC 2006

\begin{abstract}
The photosensitizing perylenequinone toxin elsinochrome A (EA) is produced in culture by the bindweed biocontrol fungus Stagonospora convolvuli LA39 where it apparently plays a pathogenicity related role. We investigated the fate of EA with reference to its stability under different temperature and light conditions. EA remained stable when boiled in water at $100^{\circ} \mathrm{C}$ for $2 \mathrm{~h}$. Similarly, exposing EA to $3-27^{\circ} \mathrm{C}$ in the dark for up to 16 weeks did not affect its stability either in dry or in aqueous form. However, results from irradiation experiments indicate that direct photolysis may be a significant degradation pathway for EA in the environment. EA either in dry form or dissolved in water was degraded by different irradiation wavelengths and intensities, with degradation plots fitting a first order rate kinetics. EA degraded faster if exposed in aqueous form, and at higher quantum flux density $\left(\mu \mathrm{mol} \mathrm{s}^{-1} \mathrm{~m}^{-2}\right)$. Sunlight was more effective in degrading EA than artificial white light and ultraviolet radiations (UV-A or UV-B). Exposing EA to natural sunlight, particularly, during the intense sunshine $(1,420$ $1,640 \mu \mathrm{mol} \mathrm{s}^{-1} \mathrm{~m}^{-2}$ ) days of 30 July to 5 August 2004
\end{abstract}

M.O. Ahonsi · D. Boss - M. Maurhofer - G. Défago Phytopathology Group, Institute of Plant Sciences, Swiss Federal Institute of Technology, CH-8092, Zürich, Switzerland

M.O. Ahonsi (《)

Present address: River Basin Research Center, Gifu

University, 1-1 Yanagido, Gifu 501-1193, Japan

e-mail: mo_ahonsi@yahoo.com in Zurich caused the substance to degrade rapidly with half-life under such condition only $14 \mathrm{~h}$. This implies that should EA gets into the environment, particularly on exposed environmental niches, such as on plant surfaces through biocontrol product spray, or released from shed diseased leaves, it may have no chance of accumulating to 'level of concern'. Furthermore, a toxicity assay using Trichoderma atroviride $\mathrm{P} 1$ as biosensor showed that photo-degraded EA was not toxic, indicating that no stable toxic by-products were left.

Keywords Biological control agents (BCAs) . Convolvulus - Environmental contamination and toxicity - Fungal metabolites $\cdot$ High performance liquid chromatography (HPLC) - Photo-degradation . Photolysis - Photo-sensitizers - Risk assessment . Stability

\section{Introduction}

Man has increasingly become conscious of effects of chemicals in his environment, particularly, since the publication of Rachel Carson's 'Silent Spring' (Carson, 1962). The growing public sensitivity to environmental pollution by chemical pesticides is compounded by the problem of pest resistance to these chemicals. This has led to increased interest in the search for environmentally benign crop protection strategies such as the use of microbial Biological Control Agents (BCAs) as alternatives to synthetic chemical pesticides in agriculture. 
However, this 'deliberate introduction' of microbes into the environment as plant protection agents has also suffered from the increasing public awareness of the risk of pesticides in the food-chains. This is particularly due to the fact that some microbes have been proven to produce chemicals (as secondary metabolites) that are highly toxic to man and his livestock (Bove, 1970; Shotwell et al., 1969, 1971; Joffe, 1986; Chu and Li, 1994; Lubulwa and Davis, 1994; Abramson, 1998).

The ever-increasing public awareness and sensitivity has continued to put pressure on both the academic and industrial plant protection scientists to become more 'environmentally responsible' as they work towards providing solutions to pest and disease problems in agriculture. This has indeed given birth to a recently emerged and expanding field of plant protection science called 'Risk Assessment'. Determination of the environmental fate of pesticides or of major toxic metabolites of fungal BCAs has become an established step in the development and commercialization of plant protection products, particularly, in Europe. While progress made in recent years in the development and commercialization of fungal $\mathrm{BCAs}$ is in accordance with the European Commission (EC) common agricultural policy and the global consensus to reduce synthetic chemicals in the environment, one of the major limitations to the registration and subsequent commercialization of fungal BCAs has been the requirement of risk assessment of their secreted metabolites (Strasser et al., 2000). This article reports on the potential environmental fate of elsinochrome A (EA), a major toxic metabolite produce in culture by the field and hedge bindweeds biocontrol fungus, Stagonospora convolvuli LA39 (Nicolet and Tabacchi, 1999; Ahonsi et al., 2005). Even though, in planta production of this metabolite by the fungal BCA has not been detected, the ability to produce the substance in certain artificial growth media seems to be an innate characteristic of isolates of Stagonospora which are aggressive on field and hedge bindweeds (Ahonsi et al., 2005). EA is a photosensitizing perylenequinone toxin typically produced by Elsinöe (and its anamorph Sphaceloma) spp. (Chen et al., 1966; Weise et al., 1987; Meille et al., 1989). Among photosensitizing perylenequinones, cercosporin which is closely related to EA (Table 1) (Weise et al., 1987; Meille et al., 1989) and is a pathogenicity determinant in Cercospora spp. (Daub and Ehrenshaft, 2000) is the most studied. These substances absorb light energy and become energetically activated, reacting with molecular oxygen to form both radical and non-radical species of activated oxygen, which have near-universal toxicity (Daub and Ehrenshaft, 1993; 2000). Cercosporin has been shown to generate both singlet oxygen $\left({ }^{1} \mathrm{O}_{2}\right)$ and superoxide $\left(\mathrm{O}_{2}{ }^{-}\right)$in vitro when illuminated, but the former is primarily responsible for its high toxicity (Daub and Hangarter, 1983). Cercosporin is known to be almost universally toxic to living cells, with toxic effects well documented against mice, many bacteria and

Table 1 Chemical properties of elsinochrome A and the closely related perylenequinone photosensitizing fungal toxin cercosporin

Fungal toxin $\quad$ Chemical structure \begin{tabular}{l}
$\begin{array}{l}\text { Chemical } \\
\text { formula }\end{array}$ \\
\hline Elsinochrome $A$ \\
weight
\end{tabular}


fungi, plants, and human cells at micromolar concentrations (Balis and Payne, 1971; Daub, 1982; Tamaoki and Nakano, 1990; Ballio, 1991; Batchavora et al., 1992; Daub and Ehrenshaft, 1993; 2000). Toxicity of EA is less documented. However, elsinochromes (such as B1, $\mathrm{B} 2, \mathrm{C} 1$ and $\mathrm{C} 2$ ) have been shown to have photodynamic inhibitory effects on proteinkinase C (Arnone et al., 1993). The closeness in structure of EA to cercosporin (Table 1) suggests a possible similarity in function and mode of action. Indeed, the phototoxic effect of EA on human cells was recently reported (Ma et al., 2003). These authors found EA concentrations as low as 1 $\mu \mathrm{M}$ and $10 \mu \mathrm{M}$ to induce up to $41 \%$ and $53 \%$ apoptosis on the human cell line Hce-8693 after 20 min irradiation.

The study described in this article aimed to determine the potential importance of irradiation and temperature on the degradation of EA, and to determine if degraded EA is potentially toxic compared with the non-degraded substance.

\section{Materials and methods}

\subsection{Test substance and organic solvents}

EA (Table 1) used in this study was of $>98 \%$ purity grade and was purchased in small screw-capped vials from Specs BV (Delft, The Netherlands) in granular form. Once it was received from the company, it was stored in the dark at $-20^{\circ} \mathrm{C}$ in a frost- free refrigerator. Organic solvents used included acetonitrile $\left(\mathrm{CH}_{3} \mathrm{CN}\right)$ [HPLC gradient grade $\geq 99.9 \%$ (GC); Fluka Chemie AG, Buchs, Switzerland]; tetrahydrofuran $\left(\left(\mathrm{C}_{2} \mathrm{H}_{4}\right)_{2} \mathrm{O}\right)$ [HPLC purity grade $99.9+\%$; Sigma-Aldrich, D-8955 Steinheim Germany]; and ethyl acetate $\left(\mathrm{CH}_{3} \mathrm{COOC}_{2} \mathrm{H}_{5}\right)$ [Erne $\mathrm{AG}$, Dällikon, Switzerland].

\subsection{High performance liquid chromatography} (HPLC) analysis

For all experiments, analysis of EA samples by HPLC was done in a Hewlett Packard 1090 liquid chromatograph equipped with a diode-array detector. A reverse phase column, CC $250 \times 4 \mathrm{~mm}$ Nucleosil 120-5 C18 (Macherey-Nagel, Germany) was used, and the temperature of the column was $28^{\circ} \mathrm{C}$. Injection volume was 25 $\mu \mathrm{l}$, and the samples were eluted with $80 \%$ acetonitrile, $20 \% \mathrm{ddH}_{2} \mathrm{O}$ (acidified with $0.045 \% \mathrm{H}_{3} \mathrm{PO}_{4}$ ) for $10 \mathrm{~min}$ at a flow rate of $1 \mathrm{ml} \mathrm{min}^{-1}$. Detection of EA was initially viewed at $217,230,242$, and $254 \mathrm{~nm}$ at 4.9-5.1 min after injection (retention time), but quantification was done at $230 \mathrm{~nm}$ (Fig. 1).

\subsection{Effect of temperature on the stability of EA}

Three separate experiments were conducted to evaluate the effect of temperature on the stability of EA, and each of these experiments was replicated three times and repeated once, giving two runs (experimental runs) per experiment.

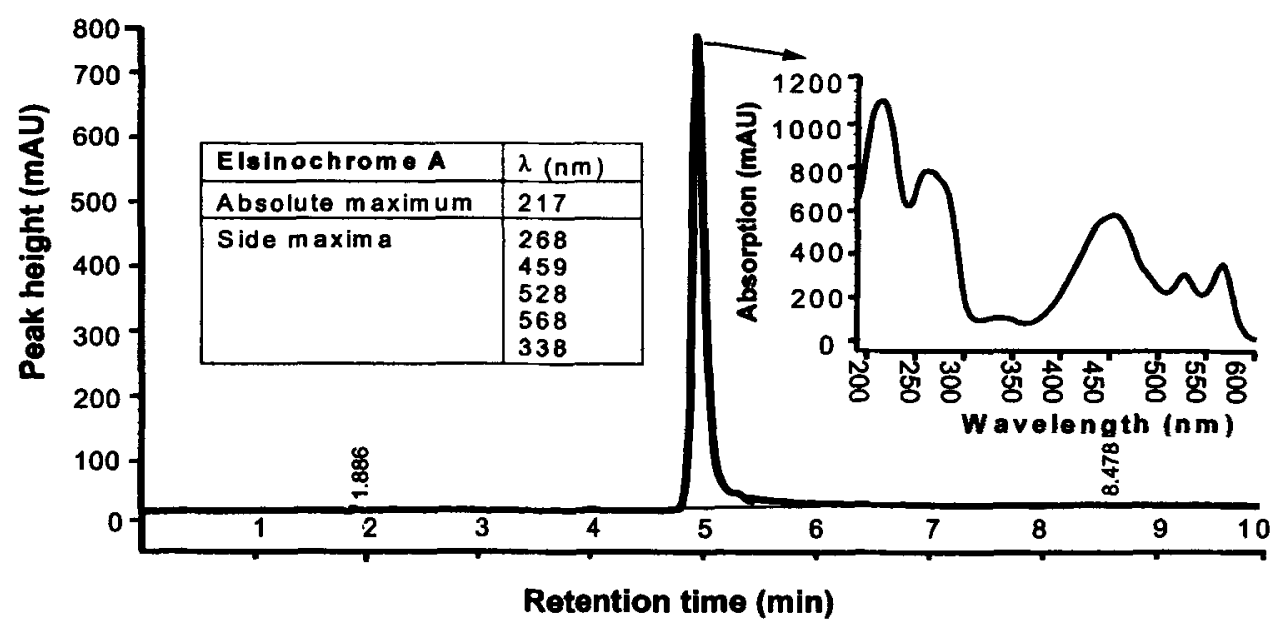

Fig. 1 High performance liquid chromatography peak and UV absorption spectrum of elsinochrome A. A reverse phase nucleosil C 18 column was used. $14.7 \mathrm{nmol}$ of pure elsinochrome $A$ was analysed, and detection at $230 \mathrm{~nm}$ is presented 


\subsubsection{Effect of high temperature on the stability of $E A$}

The first temperature experiment was conducted to determine the stability of EA at high temperatures of $40^{\circ} \mathrm{C}$ to $100^{\circ} \mathrm{C}$ (in boiling water) on short time exposure in the laboratory. From a $183.8 \mu \mathrm{M}$ stock solution of EA made in acetonitrile containing $1.8 \%$ tetrahydrofuran (THF), $50 \mu l$ each were distributed in $1.1 \mathrm{ml}$ conical bottom glass vials (Infochroma AG, Zug, Switzerland). The solvent was evaporated under argon gas stream, leaving the dried EA in the vials before closing the vials with crimp caps. The treatments in the first experimental run were vials kept for $30 \mathrm{~min}$ or $1 \mathrm{~h}$ in a water-bath adjusted to 40,60 , and $80^{\circ} \mathrm{C}$, and in boiling water maintained at $100^{\circ} \mathrm{C}$ (by addition of $\mathrm{NaCl}$ ). In the second experimental run, durations of exposure were increased from $30 \mathrm{~min}$ and $1 \mathrm{~h}$ to $1 \mathrm{~h}$ and $2 \mathrm{~h}$ respectively. After the heat treatment, the dry EA in the vial was re-dissolved in $100 \mu \mathrm{l}$ of acetonitrile/THF (4:1) for analysis by HPLC. Controls were EA samples in vials dried under argon gas stream, but without any heat treatment.

\subsubsection{Effect of temperature on stability of EA in dry form}

The second temperature experiment was conducted to determine the stability of EA in dry form in the dark at 3 to $27^{\circ} \mathrm{C}$. Glass vials containing dried EA prepared as described previously in Section 2.3.1, were kept in the dark at $3,8,15,20$ and $27^{\circ} \mathrm{C}$. After 1 day, 3 days, 1 week, 2 weeks, 4 weeks, 8 weeks, 12 weeks and 16 weeks, three vials (replicates) each were taken from the various temperatures and the EA was dissolved in 100 $\mu$ l of acetonitrile/THF $(4: 1)$ for HPLC analysis. The control samples were similarly prepared as those kept at various temperatures, but were analysed by HPLC immediately (day 0 ).

\subsubsection{Effect of temperature on the stability of EA dissolved in water}

The third temperature experiment was conducted to test the effect of temperature on stability of EA dissolved in water and kept in the dark at $3^{\circ} \mathrm{C}-27^{\circ} \mathrm{C}$. Since pure EA is not readily soluble in water, aqueous solution of the substance was made by initially dissolving $4 \mathrm{mg}$ of the pure substance in $400 \mu \mathrm{l}$ THF, then gradually in water through series of mixing and centrifugation to a final $20 \mathrm{ml}$ aqueous solution ( $\mathrm{pH} 6.5$ ) containing $2 \%$ THF. $100 \mu \mathrm{l}$ of EA solution was distributed into sterile 0.6 ml clear microtubes (MCT-060-C, Genuine AXYGEN Quality, Axygen Scientific, Inc. 33170 Central Ave. Union City, CA 94587, USA), and kept in the dark at 3, $8,15,20$ and $27^{\circ} \mathrm{C}$ for 1 day, 3 days, $1 \mathrm{wk}, 2 \mathrm{wks}, 4 \mathrm{wks}$, $8 \mathrm{wks}$, and $10 \mathrm{wks}$ before HPLC analysis. The control tubes were analyzed by HPLC immediately. For HPLC analysis, $20 \mu \mathrm{l}$ of THF and $80 \mu \mathrm{l}$ of acetonitrile were added to the EA solution in microtube directly, mixed by pipetting and vortexing, followed by centrifugation at high speed for $3 \mathrm{~min}$. The supernatant was transferred into HPLC glass vials for analysis.

\subsection{Effect of white light on stability of EA}

Two separate experiments were conduct to test the effect of white light on the stability of EA in dry and in aqueous forms respectively, and each of the two experiments were replicated three times and repeated once.

\subsubsection{Effect of white light on stability of EA in dry form}

This experiment was conducted to determine the stability of EA exposed to continuous white light. The two white light sources tested were, cool white light (TL 20W/55, DE LUXE, Philips, France) at $20^{\circ} \mathrm{C}$ and incandescent white light (TL D 18W/82, Philips, Holland) at $27^{\circ} \mathrm{C}$. Using a photometer model LI-185B (LI-COR Inc. USA), for each of these two light treatments, the illuminance (on the samples) was measured in lux. Quantum Flux Density (QFD) (the number of photons in the $400-700 \mathrm{~nm}$ waveband incident per unit time on a unit surface) (in $\mu \mathrm{mol} \mathrm{s} \mathrm{s}^{-1} \mathrm{~m}^{-2}$ ) on the EA samples was estimated using the relationship: $1000 \mathrm{Lux}=1 \mathrm{Klux}=19.5 \mu \mathrm{mol} \mathrm{s} \mathrm{m}^{-1} \mathrm{~m}^{-2}$ (Bigs, 1985). The estimated $Q F D$ values were $35.1 \mu \mathrm{mol}$ $\mathrm{s}^{-1} \mathrm{~m}^{-2}$ and $54.6 \mu \mathrm{mol} \mathrm{s}^{-1} \mathrm{~m}^{-2}$ at 20 and $27^{\circ} \mathrm{C}$, respectively. Glass vials containing dried EA were prepared as described in Section 2.3.1. At 1 day, 3 days, 1 week, 2 weeks, 4 weeks, 8 weeks, 12 weeks and 16 weeks, three vials (replicates) each were taken from the various temperatures and dissolved in $100 \mu \mathrm{l}$ of acetonitrile/THF (4:1) for HPLC analysis. There were two sets of control, samples of which were prepared the same way as those exposed to white light at 20 and $27^{\circ} \mathrm{C}$. One control consisted of vials kept at the 
same temperatures $\left(20\right.$ and $\left.27^{\circ} \mathrm{C}\right)$ in dark which were analysed at 1 day, 3 days, 1 week, 2 weeks, 4 weeks, 8 weeks, 12 weeks and 16 weeks as those of the light treatments. The second control consisted of vials which were analysed by HPLC immediately (at day 0 ).

\subsubsection{Effect of white light on the stability of EA dissolved in water}

Preparation of microtubes of EA solution for exposure to light and for HPLC analysis after exposure time, were the same as described previously in Section 2.3.3. The microtubes containing EA solution were kept in continuous white light at 20 and $27^{\circ} \mathrm{C}$ for 1 day, 3 days, 1 wk, 2 wks, 4 wks, 8 wks, and 10 wks before HPLC analysis. The two white light sources tested were, warm white light (TL 20W/29, Philips, Holland) at $20^{\circ} \mathrm{C}$ and incandescent white light (TL D $18 \mathrm{~W} / 82$, Philips, Holland) at $27^{\circ} \mathrm{C}$, both with the same illuminance as measured by photometer. Using the same procedure described before in Section 2.4.1, the QFD of both light treatments at 20 and $27^{\circ} \mathrm{C}$ was $54.6 \mu \mathrm{mol} \mathrm{s}^{-1} \mathrm{~m}^{-2}$. There were two sets of control, samples of which were prepared the same way as those exposed to white light at 20 and $27^{\circ} \mathrm{C}$. One control consisted of microtubes kept at the same temperatures (20 and $27^{\circ} \mathrm{C}$ ) in dark for 1 day, 3 days, 1 wk, 2 wks, $4 \mathrm{wks}, 8 \mathrm{wks}$, and $10 \mathrm{wks}$ before HPLC analysis. The second control consisted of microtubes of EA solution analysed by HPLC immediately (at day 0 ).

\subsection{Effect of natural sunlight on the stability of \\ EA dissolved in water}

Microtubes of EA solution prepared as described previously in Section 2.3.3 were placed either directly (sunlight-illuminated) or rapped in aluminium foil (non-illuminate or in the dark) in the open (daylight and night darkness) on the terrace of LFW building, ETHZentrum. Zurich. The illuminance (in lux) of sunlight on the microtubes was measured with a photometer at mid-day daily during the experiment. From these data, the QFD values in $\mu \mathrm{mol} \mathrm{s}^{-1} \mathrm{~m}^{-2}$ were estimated as described previously in Section 2.4.1. In the first experimental run ( 30 July-5 August, 2004), the microtubes were kept for 1-5 days and three tubes (replicates) were taken per treatment daily and prepared for HPLC analysis as described previously in Section 2.3.3. In the second experimental run (24 August-1 September, 2004), the microtubes were kept up to 10 days in the open.

\subsection{Effect of ultraviolet lights (UV-A and UV-B) on the stability of EA}

From a $919 \mu \mathrm{M}$ stock solution of EA made in acetonitrile/THF (4:1), samples of $50 \mu 1$ were placed onto glass slides with dents (diameter: $1.5 \mathrm{~cm}$, depth $1 \mathrm{~mm}$ ). After the solvent had dried completely, the slides were exposed to UV-A light $(315-400 \mathrm{~nm})$ at $20^{\circ} \mathrm{C}$ or UV-B light (280-315 nm) at $24^{\circ} \mathrm{C}$. Controls were kept in the dark at the same temperatures. After 1, 3, 7, 14, 21, 28 and 56 days, samples were taken, the EA in the glass slide dent was dissolved in $250 \mu \mathrm{l}$ ethyl-acetate, the solution transferred to eppendorf tubes and the solvent completely evaporated under argon gas stream. The dry probes were dissolved in $200 \mu \mathrm{l}$ acetonitrile/THF (4:1), transferred to HPLC vials for immediate HPLC analysis.

\subsection{Bioassay of photo-degraded EA for toxicity}

Toxicity of photo-degraded (sunlight illuminated) EA was performed using a highly EA-sensitive biocontrol fungus Trichoderma atroviride strain P1 described in another study conducted in our laboratory (unpublished data) as biosensor. Four-day old freshly grown fungus on malt agar was used. EA solution used for this bioassay was prepared as described previously in 2.3 .3 , but contained $7 \%$ acetonitrile instead of $2 \%$ THF as initial dissolving solvent. Three $1.5 \mathrm{ml}$ clear eppendorf tubes each containing 600 $\mu$ l EA solution were placed either directly (sunlightilluminated) or rapped in aluminium foil (nonilluminate) in the open (daylight and night darkness) on the terrace of LFW building, ETH-Zentrum, Zurich for 10 days (until the red EA solutions exposed to sunlight were completely bleached to clear solutions). After the exposure period, EA solutions in the three 1.5 $\mathrm{ml}$ tubes were pooled in a $14 \mathrm{ml}$ eppendorf tube. Four treatment samples were made by dilution as undiluted, $2 \times$ diluted, $4 \times$ diluted and $8 \times$ diluted from the illuminated EA, non-illuminated EA and the $7 \%$ acetonitrile solution included as control. Small Petri dishes $(6 \mathrm{~cm}$ diameter) were poured with $3 \mathrm{ml}$ of malt agar containing $5 \%(150 \mu \mathrm{l} /$ plate $)$ of the appropriate EA treatment 
sample solution. The controls were plates poured with $3 \mathrm{ml}$ malt agar containing $5 \%$ of the corresponding dilution of $7 \%$ acetonitrile solution. The amount of EA contained per Petri dish was estimated by HPLC analysis of three replicate samples each of the undiluted illuminated and non-illuminated EA solutions. The bioassay agar plates were inoculated with the fungus, by placing a $5 \mathrm{~mm}$ agar plug of the fresh 4 days grown culture at the centre of the $6 \mathrm{~cm}$ diameter agar plate. There were three replicates for each treatment sample, with each replication made from a different fungal culture plate but the same plate for all the treatments. The plates were incubated at $20^{\circ} \mathrm{C}$ in continuous white light ( $35 \mu \mathrm{mol} \mathrm{s}{ }^{-1} \mathrm{~m}^{-2}$ ). After two days and three days of incubation, fungal mycelia growth in diameter was measured.

\subsection{Statistical analysis}

For all HPLC analysis data, percentage relative peak areas (relative to average peak area for the respective control) were used in comparing treatment effects on amount of EA detected by HPLC. All data were analysed in SAS (Statistical Analysis Software version 8, SAS Institute Inc., Cary, NC, USA. For the repeated experiments, data were combined in the anal$y$ sis if initial analyses showed the same pattern of variation and no significant difference between experimental runs, otherwise, they were analyzed separately. Treatments means with their standard deviations were obtained by Mean Procedure in SAS and used to construct scatter grams fitted with regression lines and equations in Microsoft Excel. From the regression equations, half-lives were calculated, taken $y$-intercept as $50 \%$. Data from the effect of high temperature experiments were analyzed by MIXED PROCEDURE in SAS, taken replication and experimental run as random variables. Similarly, toxicity data (mycelia growth in $\mathrm{cm}$ ) were subjected to analysis of variance using the MIXED PROCEDURE in SAS, taken replication as a random effect variable and treatment as fixed effect. Single-degree-of-freedom contrasts were made to test the differences between treatments and their appropriate solvent controls. Percentages of the contrast estimates were then calculated as percentage mycelial growth inhibitions resulting from the respective treatments.
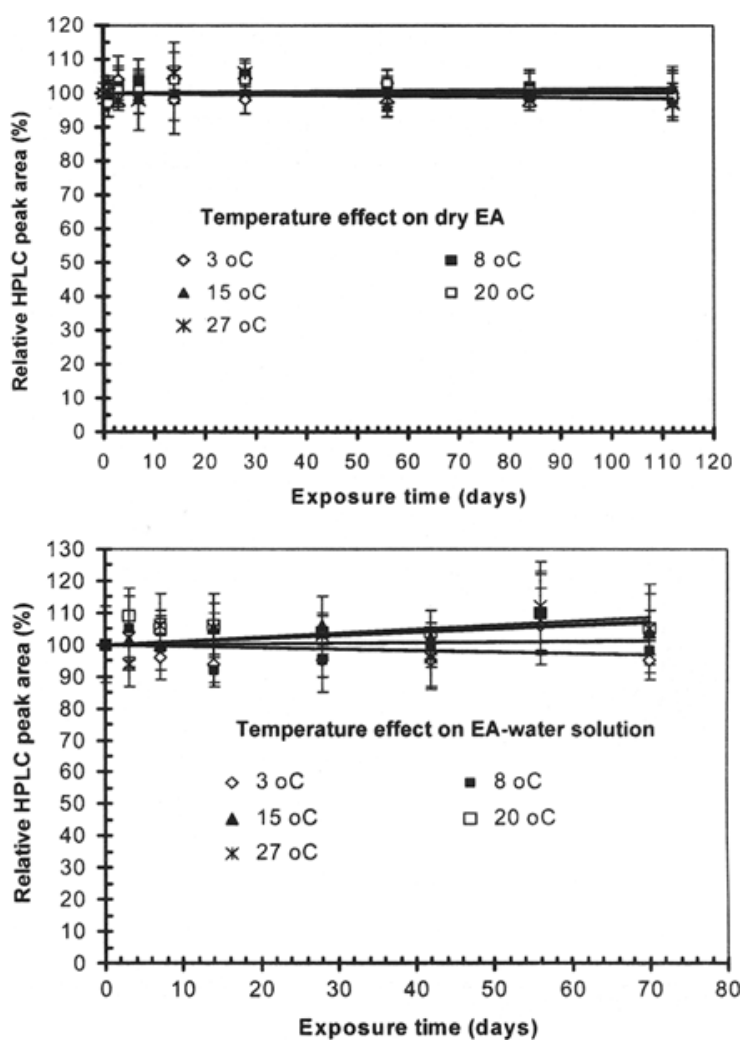

Fig. 2 Effect of temperature on the stability of elsinochrome A (EA) in dry form or dissolved in water

\section{Results}

\subsection{Effect of temperature on stability of EA}

Exposure of dry EA to temperature as high as $100^{\circ} \mathrm{C}$ (by boiling) for up to $2 \mathrm{~h}$ did not result in any significant reduction in the amount of EA detected by HPLC compared with the substance to which no treatment was applied. Similarly, the amount of EA detected as HPLC peak area did not change significantly when exposed to temperatures of $3-27^{\circ} \mathrm{C}$ in the dark either in the dry form for up to 112 days or in aqueous solution for up to 70 days (Fig. 2).

\subsection{Effect of white light on the stability of EA}

When dry EA was exposed to continuous white light of $35 \mu \mathrm{mol} \mathrm{s}{ }^{-1} \mathrm{~m}^{-2}$ at $20^{\circ} \mathrm{C}$ and $55 \mu \mathrm{mol} \mathrm{s}{ }^{-1} \mathrm{~m}^{-2}$ at $27^{\circ} \mathrm{C}$, amount of the substance detectable by HPLC gradually declined with an estimated half-life of 165 days and 130 days, respectively (Fig. 3). When aqueous solution of EA was exposed to continuous white 


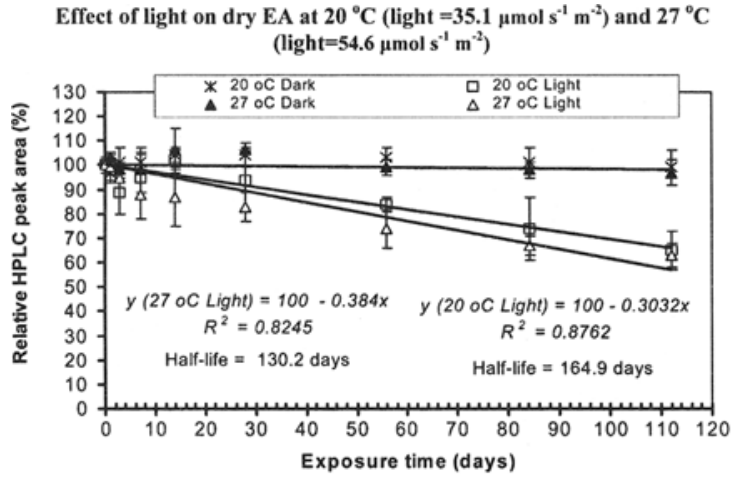

Effect of light $\left(54.6 \mu \mathrm{mol} \mathrm{s} \mathrm{m}^{-1}\right)$ on EA-water solution at $20^{\circ} \mathrm{C}$ and $27^{\circ} \mathrm{C}$

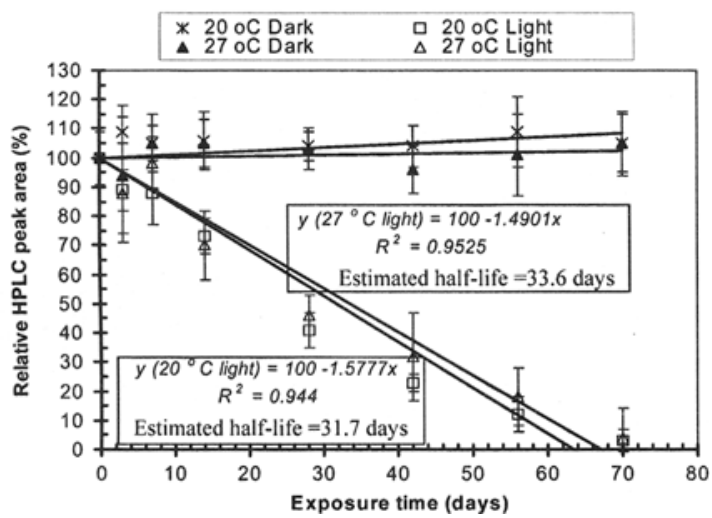

Fig. 3 Effect of white light on the stability of elsinochrome A (EA) in dry form or dissolved in water

light of $55 \mu \mathrm{mol} \mathrm{s}^{-1} \mathrm{~m}^{-2}$ at 20 and $27^{\circ} \mathrm{C}$, a more rapid degradation with an estimated half-life of 32 days and 34 days respectively, was observed (Fig. 3 ). In contrary, EA samples kept in the dark either in dry form or in solution at the same temperatures of 20 and $27^{\circ} \mathrm{C}$ remained unchanged (Fig. 3).

\subsection{Effect of natural sunlight on the stability of EA}

On exposure to the intense sunshine $(1,420-1,640$ $\mu \mathrm{mol} \mathrm{s}-1 \mathrm{~m}^{-2}$ ) days of 30 July to 5 August, 2004 (Fig. 4), EA was rapidly bleached (changed from red solution to colourless solution) and degraded with a short half-life of only $14 \mathrm{~h}$ (Fig. 5). However, EA samples kept under the same weather conditions but sheathed from sunlight by rapping in aluminium foil remained unchanged (Fig. 5). In the second experimental run conducted during the less intense sunshine days of $25 \mathrm{Au}-$ gust to 1 September, 2004 (Fig. 4), the half-life of EA exposed to sunlight was $99 \mathrm{~h}$, while the control sam-
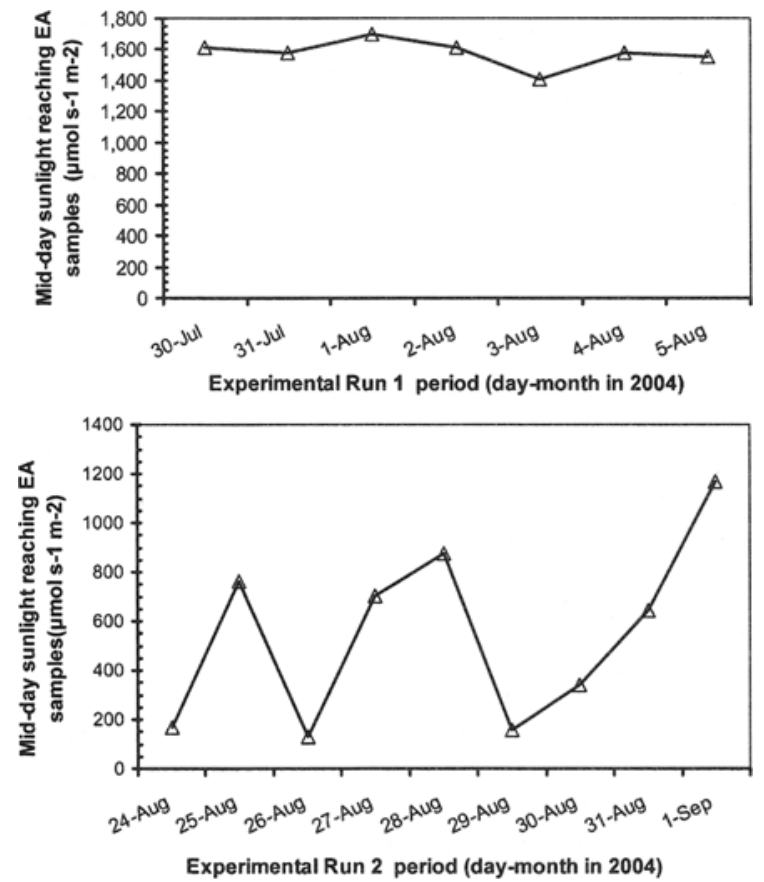

Fig. 4 Intensity of mid-day sunlight reaching elsinochrome A (EA) samples during first experimental period (30 July-5 August) and second experimental period (24 August-12 September) of investigation on effect of sunlight on EA stability

ples sheathed from sunlight also remained unchanged (Fig. 5).

\subsection{Effect of UV-A and UV-B on the stability of EA}

On exposure to UV-A and UV-B, the amount of EA decreased with half-lives of 78 days and 12 days respectively compared with samples that were not exposed (Fig. 6). In contrary, amount of EA samples kept under the same temperatures but sheathed from UV-A and UV-B remained unchanged throughout the 56 days of the experiment (Fig. 6).

\subsection{Bioassay of photo-degraded EA for toxicity}

HPLC analysis of the EA samples after exposure to sunlight for 10 days or sheathed from sunlight for the same length of time, showed that there was an estimated amount of $3.8 \mu \mathrm{M}$ EA in the samples exposed to sunlight compared with an estimated amount of $66.1 \mu \mathrm{M}$ EA in control samples sheathed from sunlight (Table 2). The mycelial growth of the 

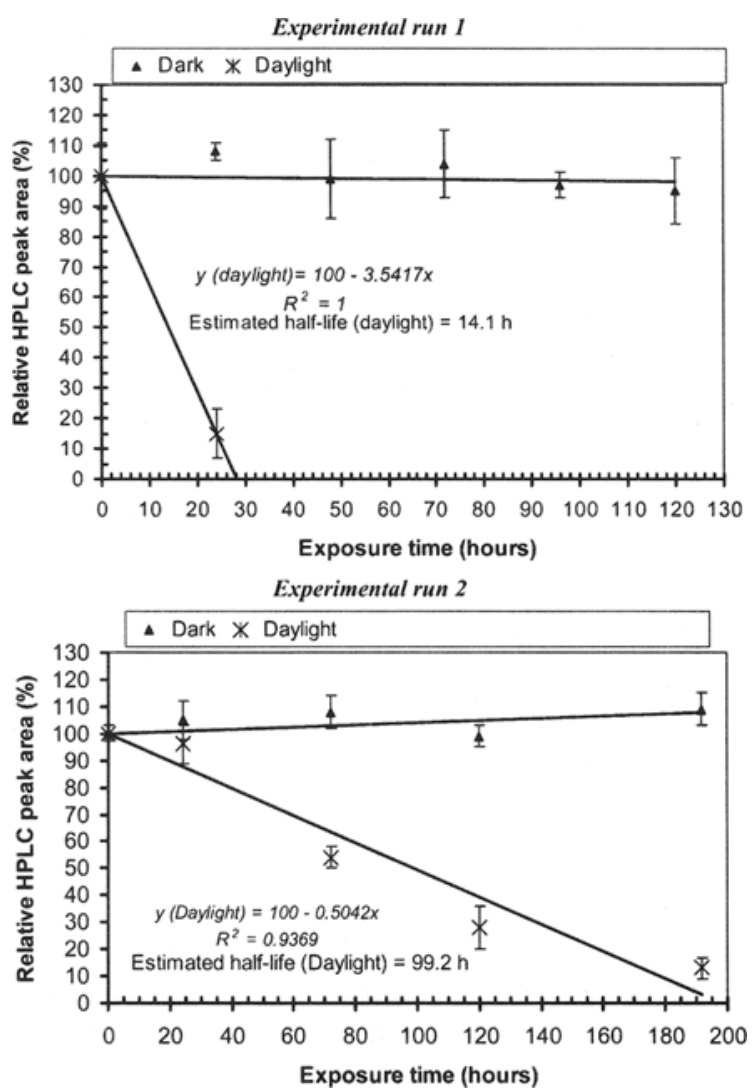

Fig. 5 Effect of natural sunlight (daylight) on the stability of elsinochrome A (EA) dissolved in water in an experiment conducted at two different periods in the summer of 2004 in Zurich

fungus Trichoderma atroviride $\mathrm{P} 1$ was significantly $(p<0.0001)$ inhibited even by the $8 \times$ diluted nonilluminated EA compared with the respective $7 \%$ solvent dilutions used as controls (Table 2). In contrary, mycelial growth of $T$. atroviride $\mathrm{P} 1$ was the same on agar plates incorporated with even the undiluted EA solution that was exposed to and degraded by sunlight as in the control plates without EA (Table 2).

\section{Discussion}

There has not been any previous report on the stability or fate of EA, or on the effect of environmental physical factors on the stability of any microbial perylenequinone toxin. However, the ability of bacteria to biodegrade cercosporin has been proven (Mitchell et al., 2002). In absence of light, EA either in dry form or as solution in water may remain stable even at maximal air or soil temperatures that could nor-
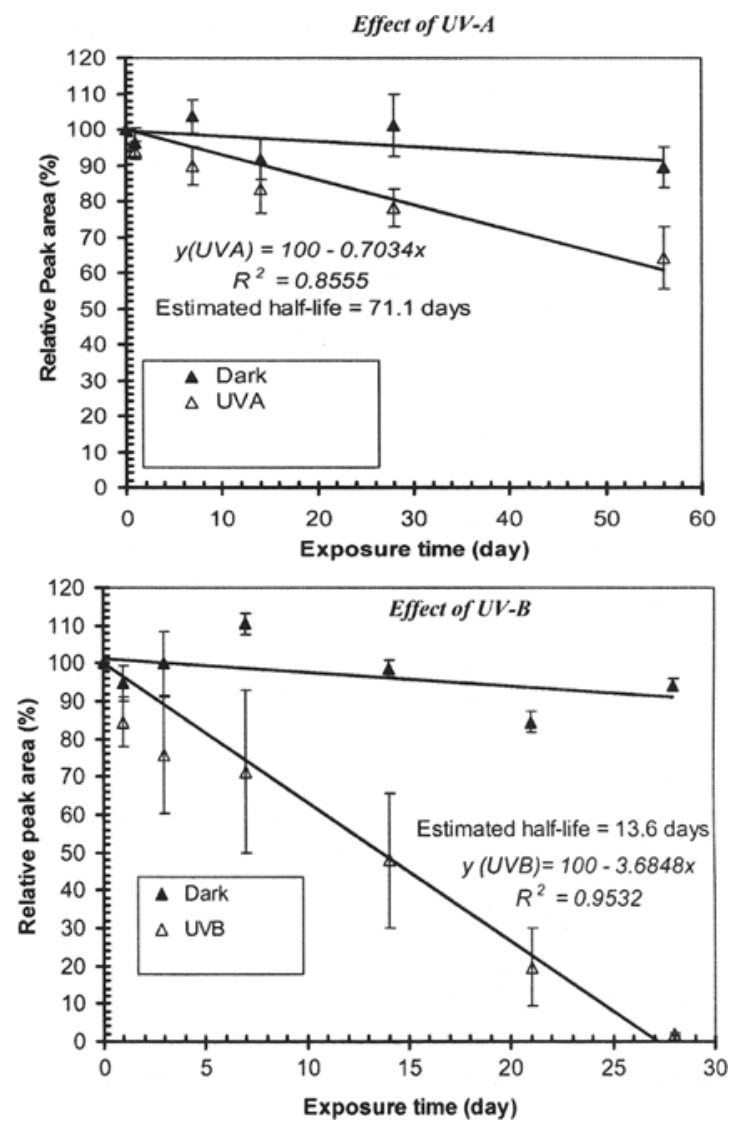

Fig. 6 Effect of UV-A and UV-B on the stability of elsinochrome $A$ in dry form

mally be found in temperate regions, particularly. Similarly, the resistance of many other fungal toxins particularly, the more studied 'mycotoxins' (specifically used for toxic chemicals produced by food poisoning fungi in the field or in storage) to high temperatures has been well reported (Chu et al., 1975; Bennett and Richard, 1996; Lowes et al., 2000; YumbeGuevara et al., 2003). In fact, as a general rule, mycotoxins are stable during food preparation and are not destroyed by cooking or baking. For instance, Yumbe-Guevara et al. (2003) found that thermal treatment of barley and wheat naturally contaminated by the Fusarium mycotoxin deoxynivalenol (DON) in electric convention oven, and gas-fired roaster showed no significant effects at temperatures below $160^{\circ} \mathrm{C}$ after 60 min of processing. Tschen et al. (1997) also reported that helvolic acid, an antibiotic fungal metabolite isolated from the pathogen Sarocladium oryzae (causal of rice sheath rot) was stable at temperatures of 22 $100^{\circ} \mathrm{C}$. However, dramatic effect of temperature on 
the degradation of some chemicals in the environment has also been reported (Vink and Vanderzee, 1995; Sanz-Asensio et al., 1997; Anthanasopoulos et al., 2004). For instance, Anthanasopoulos et al. (2004) reported that the half-lives of parathion methyl at relative humidity of 60 to $96 \%$ were 48 to 57 days at $0^{\circ} \mathrm{C}, 9.2$ to 10.5 days at $20^{\circ} \mathrm{C}$ and 1.3 to 1.5 days at $40^{\circ} \mathrm{C}$.

In contrary, the results shown in Figs, 3, 5 and 6 implicate light as a physical factor that could rapidly degrade EA in the environment. The plots of EA concentration and light exposure time relationships fit a first order rate equation of the type $\mathbf{Y}=\mathbf{a}-\mathbf{b X}$ (where $\mathbf{Y}=$ concentration of $\mathrm{EA}$ residue after exposure, $\mathbf{a}$ $=$ concentration of EA at zero exposure time, $\mathbf{b}=$ degradation rate constant, and $\mathbf{X}=$ time in day of exposure to light). The correlation coefficient squared $\left(R^{2}\right)$ for degradation of EA in dilute aqueous solution particularly, on exposure to white light, UV-B, and sunlight ranged from $0.944-1.0$ indicating a good fit and implying that EA degradation under light corresponds to a first order rate kinetics. Though our test system does not exactly reflect the natural situation of EA excreted in membranes of leaves (lipid environment), our results clearly show that photo-degradation of EA may be faster when the substance is in aqueous solution than when it is in dry form. Potentially, this is a good indication, since the toxin would normally be found in the environment in wet condition, not in dry state.

Comparing the results obtained from experiments conducted to show the effect of light, UV-A and UV-B and of natural sunlight on EA stability (Figs. 3, 5 and 6), it is clear that natural sunlight was more effective in degrading EA than artificial white light and either of the UV radiations. It is possible that EA photolysis occurs at more than one wavelength range. Solar radiation reaching the earth's surface having a wider wavelength range $(290->800 \mathrm{~nm})$ spanning through the wavelengths of UV-B, UV-A and visible light up to the infrared region (Zepp and Cline, 1977; Zepp et al., 1985; Jensen-Korte et al., 1987; Niu et al., 2004; Katagi, 2004) may provide better chance for EA photolysis. In this study, we did not diagnose what wavelength component of the solar radiation was most important or responsible for the rapid photo-degradation of EA. Zepp et al. (1995) reported that whereas visible sunlight $(400-750 \mathrm{~nm})$ hardly causes photochemical reactions, solar UV-B radiations $(280-315 \mathrm{~nm})$ and partially solar UV-A radiation $(315-400 \mathrm{~nm})$ induce various direct and indirect photochemical pro- cesses in the top level of surface waters, which can lead to a degradation of anthropogenic micro-pollutants. However, the data shown in Figs. 3, 5 and 6 probably indicate that the quantum flux density of light at the visible light region may be as important as the UV-radiations in the photo-degradation process of EA.

Only substances with UV-absorption spectra in the wavelength range of sunlight reaching the earth's surface can undergo direct interaction with sunlight and therefore have a possibility for direct photolysis (Zepp et al., 1985; Jensen-Korte et al., 1987). Jensen-Korte et al. (1987) pointed out that most chemical pesticides for instance, have UV-absorption spectra bands which fade out in the border area of $280-290 \mathrm{~nm}$ or below, hence practically, no direct photo-degradation is possible. EA is a photosensitizer, with molecular oxygen as the ubiquitous quencher (Daub and Hangarter, 1983; Daub and Ehrenshaft, 1993; 2000). Only its absolute maximum $(217 \mathrm{~nm})$ and first side maxima $(268 \mathrm{~nm})$ of the wavelength spectrum are outside the solar energy wavelengths reaching the earth surface (Fig. 1). The four side maxima at 338, 459, 528 and $568 \mathrm{~nm}$ (Fig. 1), with $459 \mathrm{~nm}$ corresponding to the maximum wavelength range ( $440-460 \mathrm{~nm}$ ) of sunlight near the ground (Katagi, 2004) suggest that EA would absorb solar energy in the UV-region reaching the earth surface, and even stronger in the visible light region. Hence, EA has a high possibility for direct photolysis under natural sunlight.

So far, there has not been any report of detection of EA from bindweeds or other environmental samples infected by S. convolvuli LA39 despite the indication that in vitro production of the substance by Stagonospora isolates of bindweeds is positively related to their pathogenic potentials (Ahonsi et al., 2005). The implication is that, if EA is excreted in the environment by this biocontrol fungus, the likelihood that such excretion (probably in parts per billion) may accumulate to a 'level of concern' in the environment may not be greater than zero. Further, the results of toxicity bioassay of photo-degraded EA (Table 2) indicate that degradation of EA does not result in any toxic lower molecular weight chemical products. Though photolysis of EA as a perylenequinone photosensitizer would be expected to generate the toxic singlet oxygen species (Daub and Hangarter, 1983; Daub and Ehrenshaft, 1993; 2000; Ma et al., 2003), these reactive species have a half-life as short as between $10^{-6}$ and $10^{-5}$ seconds (Stahl and 
Table 2 Growth of Trichoderma atroviride strain P1 as affected by photo-degraded (10 days daylight illuminated) and nondegraded (non-illuminated) elsinochrome $A(E A)$ in solution

\begin{tabular}{|c|c|c|c|c|c|}
\hline \multirow[b]{2}{*}{ Treatment } & \multirow[b]{2}{*}{$\begin{array}{l}\text { Estimated EA } \\
\text { concentration per } \\
\text { malt agar plate }(\mu \mathrm{M})^{\mathrm{a}}\end{array}$} & \multicolumn{4}{|c|}{ Mycelial growth inhibition (\%) ${ }^{b}$} \\
\hline & & $\begin{array}{l}2 \text { days after } \\
\text { inoculation }\end{array}$ & $P>\mathfrak{t}^{\mathfrak{c}}$ & $\begin{array}{l}3 \text { days after } \\
\text { inoculation }\end{array}$ & $P>t^{i}$ \\
\hline 10 days sunlight illuminated EA (undiluted) & $0.19(3.8)$ & 0.0 & 0.73 & 0.0 & 1.0 \\
\hline 10 days sunlight-illuminated EA $(2 \times$ diluted $)$ & $0.10(1.9)$ & 0.0 & 0.30 & 0.0 & 1.0 \\
\hline 10 days sunlight-illuminated EA $(4 \times$ diluted $)$ & $0.05(1.0)$ & 0.0 & 0.49 & 0.0 & 1.0 \\
\hline 10 days sunlight - illuminated EA $(8 \times$ diluted $)$ & $0.02(0.5)$ & 0.0 & 0.73 & 0.0 & 1.0 \\
\hline Non-illuminated EA (undiluted) & $3.31(66.1)$ & 43.4 & $<0.0001$ & 41.7 & $<0.0001$ \\
\hline Non-iliuminated EA $(2 \times$ diluted $)$ & $1.65(33.0)$ & 41.7 & $<0.0001$ & 37.2 & $<0.0001$ \\
\hline Non-illuminated EA $(4 \times$ diluted $)$ & $0.83(16.5)$ & 40.9 & $<0.0001$ & 34.4 & $<0.0001$ \\
\hline Non-illuminated EA $(8 \times$ diluted $)$ & $0.41(8.25)$ & 28.9 & $<0.0001$ & 22.2 & $<0.0001$ \\
\hline
\end{tabular}

${ }^{a}$ Values in parentheses represent original concentration of EA solution before mixing with agar as estimated by HPLC, while values outside parentheses represent amount of EA present in malt agar-EA mixture per agar plate.

${ }^{h}$ Calculated as percentages of contrast estimates (in SAS) between growth in treatment and the appropriate solvent control level.

${ }^{c}$ Values are levels of significance of growth inhibition (contrast between treatment and solvent control).

Sies, 2002), and are therefore, not stable in the environment.

Acknowledgments This study was conducted under the aegis of an EU project, 'Quality of Life and Management of Living Resources: Risk Assessment of Fungal Biological Control AgentsRAFBCA 2001-2004 (QLRT-2000-01391)'. Authors' participation in the RAFCA project, and research activities culminating in this research article were made possible by grant No. 00.0164-2 provided by the Swiss Federal Office of Education (OFES).

\section{References}

Abramson, D.: 1998, 'Mycotoxin formation and environmental factors,' in Mycotoxins in Agriculture and Food Safety, Singha, K.K. and Bhatnagar, D. (eds.), Marcel Dekker, New York, pp. 255-277

Ahonsi, M.O., Maurhofer, M., Boss, D., and Défago, G.: 2005, 'Relationship between Aggressiveness of Stagonospora sp. lsolates on Field and Heldge Bindweeds, and In Vitro Production of Fungal Metabolites Cercosporin, Elsinochrome A and Leptosphaerodione,' European Journal of Plant Pathology 111, 203-215

Anthanasopoulos, P.E., Kyriakidis, V., and Stavropoulos, P.: 2004, "A study on the environmental degradation of pesticides azinphos methyl and parathion methyl,' Journal of Environmental Science and Health: Part B-Pesticides, Food Contaminations, and Agricultural Wastes B39, 297309
Arnone, A., Merlini, L., Mondellil, R., Nasini, G., Ragg, E. and Scaglioni, L.: 1993, 'Structure, conformational Analysis and Absolute configuration of the perylenequinone pigments elsinochromes B1, B2, C1 and C2,' Gazetta Chimica Jtaliana 123, 131-136

Balis, C. and Payne, M.G.: 1971, 'Triglycerides and cercosporin from Cercospora beticola: Fungal Growth and Cercosporin Production,' Phytopathology 61, 1477-1484

Ballio, A.: 1991, 'Non-host-selective fungal phytotoxins- biochemical aspects of their mode of action,' Experientia 47 , 782-790

Batchvarova, R.B., Reddy, V.S., and Benett, J.: 1992, 'Cellular Resistance in Rice to Cercosporin, a Toxin of Cercospora,' Phytopathology 82, 642-646

Bennett, G.A. and Richard, J.L.: 1996, 'Influence of processing on Fusarium mycotoxins in contaminated Grains,' Food Technology 50, 235-238

Biggs, W.W.: 1985, 'Radiation Measurement,' In LI-1000 Datalogger Instruction Manual, Software Ver. 1.02, Publication No. 8510-51, LI-COR, inc., Lincoln, Nebraska

Bove, F.J.: 1970, The Story of Ergot. S. Karger, New York

Carson, R.: 1962, Silent Spring. Houghton Mifflin Co., Boston

Chen, C.T., Nakanishi, K., and Natori, S.: 1966, 'Biosynthesis of Elsinochrome A, the Perylenequinone from Elsinoe spp. 1,' Chemical and Pharmaceutical Bulletin 14, 1434-1437

Chu, F.S. and Li, G.Y.: 1994, 'Simultaneous Occurrence of Fumonisin Bl and other mycotoxins in moldy corn collected from people's Republic of China in Regions of High Incidences of Esophageal Cancer,' Applied and Environmental Microbiology 60, 847-852.

Chu, F.S., Chang, C.C., Ashoor, S.H., and Prentice, N.: 1975, 'Stability of aflatoxin B1 and ochratoxin Ain Brewing,' Applied Microbiology 29, 313-316 
Daub, M.E. and Ehrenshaft, M.: 1993, 'The photoactivated toxin cercosporin as a tool in fungal photobiology;' Physiologia Plantarum 89, 227-236

Daub, M.E. and Ehrenshaft, M.: 2000, 'The photoactive cercospora toxin cercosporin: Contributions to plant disease and fundamental Biology.' Annual Review of Phytopathology 38, $461-490$

Daub, M.E.: 1982, 'Cercosporin, a photosensitizing toxin from Cercospora species,' Phytopathology 72, 370-374

Jensen-Korte, U., Anderson, C., and Spiteller, M.: 1987, 'Photodegradation of pesticides in the presence of humic substances,' The Science of the Total Environment 62, 335-340

Joffe, A.Z.: 1986, Fusarium Species: Their Biology and Toxicology. John Wiley, New York

Katagi, T.: 2004, 'Photodegradation of pesticides on plant and soil surfaces,' Reviews of Environmental Contamination and Toxicology 182, 1-195

Lowes, K.F., Shearman, E.A., Payne, J., MacKenzie, D., Archer, D.B., Merry, R.J., and Gasson, M.J.: 2000, 'Prevention of yeast spoilage in feed and food by the yeast mycocin HMK,' Applied and Environmental Microbiology 66, 1066-1076

Lubulwa, A.S.G. and Davis, J.S.: 1994, 'Estimating the social cost of the impacts of fungi and aflatoxins in maize and peanuts,' in Highley, E., Wright, E.J., Banks, H.J. and Champ, B.R. (eds.), Stored Product Protection. CAB International, Wallingford, pp. 1017-1042

Ma, L., Tai, H., Li, C., Zhang, Y., Wang, Z.H., and Ji, W.Z.: 2003 , 'Photodynamic inhibitory effects of three perylenequinones on human colorectal carcinoma cell line and primate embryonic stem cell line,' World Journal of Gastmenterology 9, 485-490

Meille, S.V., Malpezzi, L., Allegra, G., Nasini, G., and Weiss, U.: 1989, 'Structure of Elsinochrome A: a Perylenequinone metabolite,' Acta Crystallographica, Section C, Crystal Structure Communications 45, 628-632

Mitchell, T.K., Chilton, W.S., and Daub, M.E.: 2002, 'Biodegradation of the polyketide toxin cercosporin,' Applied and Environmental Microbiology 68, 4173-4181

Nicolet, B. and Tabacchi, R.: 1999, 'Secondary metabolites produced by Stagonospora sp., a Potential Biocontrol Agent Against Bindweeds,' In Lyr, H., Russell, P.E. and Sisler, H.D. (eds.), Modern Fungicides and Antifungal Compounds II. Intercept Limited, Andover, United Kingdom, pp. 469476

Niu, J., Chen, J., Martens, D., Henkelmann, B., Quan, X., Yang, F., Seidlitz, H.K., and Schramm, K.-W.: 2004, 'The role of UV-B on the degradation of PCDD/Fs and PAHs sorbed on surfaces of spruce (Picea abies (L.) Karst.) Needles,' Science of the Total Environment 322, 231-241
Sanz-Asensio, J., Plaza-Medina, M., and Martinez-Soria, T. 1997, 'Kinetic study of the degradation of ethiofencarb in aqueous solutions,' Pesticide Science 50, 187-194

Shotwell, O.L., Hesseltine, C.W., and Goulden, M.L.: 1969, 'Ochratoxin A: Occurrence as natural contaminant of a corn sample,' Applied Microbiology 17, 765-766

Shotwell, O.L., Hesseltine, C.W., Vandegraft, E.E., and Goulden, M.L.: 1971, 'Survey of corn from different regions for aflatoxin, ochratoxin, and zearalenone,' Cereal Science Today 16. 266-273

Stahl, W. and Sies, H.: 2002, 'Introduction: Reactive Oxygen Species,' Research Monographs: Reactive Oxygen Species, Instut für Physiologische Chemie 1, HeinrichHeine-Universität Düsseldorf

Strasser, H., Vey, A., and Butt, T.M. : 2000, 'Are there any risks in using entomopathogenic fungi for pest control, with particular Reference to the Bioactive Metabolites of Metarhizium, Tolypocladium and Beauveria species?,' Biocontrol Science and Technology 10, 717-735

Tamaoki, T. and Nakano, H.: 1990, 'Potent and specific inhibitors of protein kinase $\mathrm{C}$ of microbiologic origin,' Biotechnology 8, 732-735

Tschen, J.S.M., Chen, L.L., Hsieh, S.T., and Wu, T.S.: 1997, 'Isolation and phytotoxic effects of helvolic acid from plant pathogenic fungus Sarocladium oryzae,' Botanical Bulletin of Academia Sinica 38, 251-256

Vink, J.P.M. and Vanderzee, S.E.A.T.: 1995, 'Some physicochemical and environmental factors affecting transformation rates and sorption of the herbicide metamitron in soil,' Pesticide Science 46, 113-119

Weiss, U., Merlini, L., and Nasini, G.: 1987, 'Naturally occurring perylenequinones,' in Progress in the Chemistry of Organic Natural Products. Herz, W., Grisebach, H., Kirby, G.W. and Tamm, C.H. (eds.), Springer-Verlag, Vienna 52, pp. 1-71

Yumbe-Guevara, B.E., Imoto, T., and Yoshizawa, T.: 2003, 'Effects of heating procedures on deoxynivalenol, nivalenol and zearalenone levels in naturally contaminated barley and wheat,' Food Additives and Contaminants 20, 11321140

Zepp, R.G. and Cline, D.M.: 1977, 'Rates of direct photolysis in aquatic environment,' Environmental Science and Technology 11, 359-366

Zepp, R.G., Callaghan, T.V., and Erickson, D.J.: 1995, 'Effects of increased solar ultraviolet radiation on biogeochemical cycles,' Ambio 24, 181-187

Zepp, R.G., Schlotzauer P.F., and Sink, R.M.: 1995, 'Photosensitized Transformations Involving Electronic Energy Transfer in Natural Waters: Role of Humic Substances,' Environmental Science and Technology 19, 74-81 